\title{
PENGARUH BIAYA CORPORATE SOCIAL RESPONSIBILITY TERHADAP LABA BERSIH PERUSAHAAN PADA PT. UNITED TRACTOR, TbK
}

\author{
Jessica Wajongkere ${ }^{1}$, Lintje Kalangi ${ }^{2}$, Robert Lambey ${ }^{3}$ \\ ${ }^{1,2,3}$ Fakultas Ekonomi dan Bisnis, Jurusan Akuntansi, Universitas Sam Ratulangi, Jl. Kampus Bahu, Manado, \\ 95115, Indonesia \\ E-mail : Jessicawajongkere19@gmail.com
}

\begin{abstract}
Corporate Social Responsibility is a continuing commitment by the business community to act ethically and contribute to the economic development of the local community and the wider community, along with the improvement of the living standards of workers and their families (Wibisono 2007). The purpose of this study is to determine the influence of CSR costs on the company's of net profit on PT. United Tractor, Tbk. This research uses simple linear regression analysis method. The type of data used is quantitative data obtained from secondary data. The results showed that there is no influence between the two variables (corporate social responsibility cost to net income of the company). Based on t-test, $t$-table> t-count $(3,182>-2,074)$ and significant 0,130 where this value> 0,05 meaning there is no influence between independent variable to dependent variable.
\end{abstract}

Keywords: Cost of Corporate Social Responsibility, Net income

\section{PENDAHULUAN}

Perusahaan yang berhasil adalah perusahaan yang mampu menghadapi persaingan yang terjadi di dalam dunia usaha. Keberhasilan usaha pada hakikatnya adalah keberhasilan dari bisnis mencapai tujuannya, dan suatu bisnis dikatakan berhasil apabila mendapat laba, karena laba adalah tujuan dari seseorang melakukan bisnis (Henry Faizal Noor, 2007:397). Indikator lainnya untuk mencapai keberhasilan sebuah perusahaan dalam memenangkan persaingan di dunia usaha, yaitu profit dan pertumbuhan. Peningkatan profit ditandai dengan semakin meningkatkan tingkat penjualan produk di dalam pasar. Pertumbuhan ditandai dengan semakin meningkatkanya nilai investasi yang ditanamkan dalam perusahaan. Profit dan pertumbuhan memang merupakan indikator keberhasilan perusahaan. Selain profit dan pertumbuhan ada hal lain yang tak kalah pentingnya yaitu keberlanjutan (sustainability) (Rachmawati (2010:1). Sustainability report (laporan keberlanjutan) merupakan praktek pengukuran, pengungkapan dan upaya akuntabilitas dari sustainability activities yang bertujuan untuk tercapainya sustainable development (Global Reporting Initiative,2011). Perusahaan yang mempertimbangkan pengembangan yang berkelanjutan (sustainable development) akan dapat meningkatkan nilai perusahaan karena dukungan yang diperoleh dari stakeholder baik internal maupun eksternal, seperti konsumen, karyawan, investor, regulator, pemasok maupun kelompok lainnya.

Pengungkapan sustainability report yang meliputi aspek ekonomi, sosial, dan lingkungan didukung dengan adanya penerapan tanggung jawab sosial perusahaan (corporate social responsibility). Corporate social responsibility merupakan komitmen perusahaan atau dunia bisnis untuk berkontribusi dalam pengembangan ekonomi yang berkelanjutan dengan memperhatikan tanggung jawab sosial perusahaan dengan menitikberatkan pada keseimbangan antara perhatian terhadap aspek ekonomis, sosial dan lingkungan (Untung, 2014). Penerapan program-program corporate social responsibility tentunya membutuhkan biaya tersendiri untuk merealisasikannya dan hal ini akan berpengaruh kepada profit perusahaan. Hasil penelitian yang dilakukan oleh Riska Wanda (2013) dengan judul "pengaruh penerapan corporate social responsibility terhadap profitabilitas pada perusahaan 
pertambangan di BEI" menunjukkan bahwa penerapan corporate social responsibility berpengaruh positif signifikan terhadap ROA dan ROE perusahaan.

Berdasarkan penelitian yang dilakukan sebelumnya dengan hasil penelitian yang berbeda, maka peneliti tertarik melakukan penelitian pada PT. United Tractor, Tbk. Perusahaan ini merupakan salah satu perusahaan dalam bidang penjualan alat berat terbesar di Indonesia. Perusahaan ini menerapkan corporate social responsibility dengan baik setiap tahunnya dengan mengeluarkan biaya CSR yang cukup besar. Biaya CSR yang cukup besar setiap tahunnya tentu berpengaruh kepada laba perusahaan. Penelitian ini bertujuan untuk mengetahui pengaruh biaya corporate social responsibility terhadap laba bersih perusahaan pada PT. United Tractor, Tbk

\section{TINJAUAN PUSTAKA}

\subsection{Akuntansi Manajemen}

Akuntansi manajemen adalah salah satu cabang ilmu akuntansi yang menghasilkan informasi untuk manajemen atau pihak intern perusahaan. pengguna utama informasi akuntansi manajemen adalah para manajer, yang bertugas merencanakan kegiatan, menerapkan rencana, dan mengarahkan serta mengendalikan kegiatan organisasi tersebut atau berjalan sesuai rencana (Krismaji \& Anni Aryani, 2011).

\subsection{Corporate Social Responsibility}

The CSR are set of standards that company subscribes to in order to make positive impact on society. It also means how organisation behave ethically and contribute to economic development of society by improving the quality of life of the local community and society at large (Odetayo, Adeyemi, Sajuyigbe, 2014) yang berarti bahwa, CSR adalah standar yang diikuti oleh perusahaan agar memberi dampak positif pada masyarakat. Ini juga berarti bagaimana organisasi berperilaku etis dan berkontribusi terhadap pembangunan ekonomi masyarakat dengan meningkatkan kualitas hidup masyarakat setempat masyarakat dan masyarakat luas.

\subsection{Laba Bersih}

Laba adalah kelebihan penghasilan diatas biaya selama satu periode akuntansi.(Harahap , 2009:113). Laba (profit) juga memiliki peranan tersendiri bagi sebuah perusahaan (M.Nafarin, 2007 : 23) : 1) Laba adalah efesiensi usaha setiap perusahaan sekaligus merupakan suatu kekuatan pokok agar perusahaan dapat tetap bertahan untuk jangka pendek dan jangka panjang perusahaan 2) Laba adalah balas jasa atas dana yang ditanam perusahaan. 3) Laba merupakan salah satu sumber dana usaha perusahaan. 4) Laba merupakan sumber dana jaminan surat para karyawan. 5) Laba merupakan daya tarik bagi pihak ketiga yang ingin menanamkan dananya

\section{METODE PENELITIAN}

Jenis penelitian yang dilakukan dalam penelitian ini adalah penelitian kuantitatif mengenai pengaruh biaya corporate social responsibility terhadap laba bersih perusahaan pada PT. United Tractor, Tbk Penelitain ini dilakukan pada PT. United Tractor, Tbk. Penelitian dilakukan selama 2 bulan yaitu bulan Februari-Maret 2017. Sumber data yang digunakan dalam penelitian ini adalah data sekunder. Dalam penelitian ini data sekunder diperoleh dari website resmi perusahaan www.unitedtractor.com.id. Penelitian ini terdiri dari dua variabel yaitu variabel independen dan variabel dependen. Variabel independen yaitu biaya coporate social responsibility yang dilihat dari jumlah biaya yang dikeluarkan perusahaan pada tahun 2011-2015. Variabel dependen yaitu laba bersih yang dilihat dari berapa besar jumlah laba bersih yang diperoleh tahun 2011-2015. Metode analisis yang digunakan untuk menganalisis data dalam penelitian ini adalah metode analisis regresi 
sederhana untuk melihat seberapa besar pengaruh biaya corporate social responsibility terhadap laba bersih perusahaan.

\section{HASIL PENELITIAN DAN PEMBAHASAN}

\subsubsection{Program Corporate Social Responsibility PT. United Tractors Tbk}

Corporate social responsibility (CSR) pada PT. United Tractors, Tbk dilakukan pada perusahaan menjadi 5 pilar yaitu, UTREES (program yang dilakukan dengan cara menanam pohon di berbagai lokasi di sekitar area operasional), UTFUTURE (program yang dilakukan dengan mengembangkan pendidikan), UTGROWTH (program yang dilakukan dengan tujuan pengembangan masyarakat khususnya untuk memperbaiki keadaan ekonomi masyarakat), UTCARE (Program yang berhubungan dengan kesehatan yang dilakukan khususnya untuk semua pemangku kepentingan perusahaan) dan UTACTION (program yang dilakukan perusahaan saat mengalami situasi darurat seperti bencana alam).

\subsubsection{Biaya Corporate Social Responsibility}

Berdasarkan hasil penelitian, PT. United Tractor, Tbk melakukan 5 pilar dalam menjalankan corporate social responsibility dan peneliti mengambil data selama 5 tahun (2011-2015). Berikut ini disajikan data biaya CSR (corporate social responsibility) selama periode tersebut dapat dilihat pada tabel berikut :

Tabel 1 : Biaya program CSR PT. United Tractor, Tbk tahun 2011-2015
\begin{tabular}{|c|c|}
\hline Tahun & $\begin{array}{c}\text { Biaya Anggaran CSR } \\
(\text { Rp) }\end{array}$ \\
\hline 2011 & $31,621,000,000$ \\
\hline 2012 & $49,624,000,000$ \\
\hline 2013 & $46,830,000,000$ \\
\hline 2014 & $120,510,000,000$ \\
\hline 2015 & $123,600,000,000$ \\
\hline
\end{tabular}

Sumber : laporan keberlanjutan CSR PT.United Tractor,Tbk Tahun 2011-2015

Berdasarkan tabel 4.1 dapat dilihat bahwa tahun 2011 biaya CSR PT.United Tractor, Tbk sebesar Rp. 31.621.000.000. Pada tahun 2012 meningkat sebesar Rp. 49.624.000.000. Tahun 2013 kembali menurun sebesar Rp. Rp. 46.830.000.000. Pada tahun 2014 biaya CSR sangat meningkat menjadi Rp. 120.510.000.000. Tahun 2015 meningkat sebesar Rp. 123.600.000.000.

\subsubsection{Laba Bersih PT. United Tractors, Tbk}

Berdasarkan hasil penelitian tentang laba perusahaan pada PT. United Tractors, Tbk selama 5 tahun (2011-2015), laba perusahaan mengalami naik turun dalam pencapaian laba yang diinginkan. Berikut ini disajikan data laba bersih perusahaan selama periode tersebut dapat dilihat pada tabel berikut :

Tabel 2 : Jumlah laba bersih`setelah pajak PT. United Tractor, Tbk tahun 2011-2015

\begin{tabular}{|c|c|}
\hline Tahun & $\begin{array}{c}\text { Laba Bersih Setelah Pajak } \\
(\mathrm{Rp})\end{array}$ \\
\hline 2011 & 5.899 .506 .000 \\
\hline 2012 & 5.753 .342 .000 \\
\hline 2013 & 4.798 .778 .000 \\
\hline 2014 & 4.839 .970 .000 \\
\hline 2015 & 2.792 .439 .000 \\
\hline
\end{tabular}

Sumber : laporan tahunan (Data sudah diolah)Tahun 2011-2015

Berdasarkan pada tabel 4.2 dapat dilihat bahwa pada tahun 2011 laba bersh perusahaan PT. United Tractor, Tbk sebesar Rp. 5.899.506.000 dan pada tahun 2012 
mengalami penurunan sebesar Rp. 5.753.342.000. Tahun 2013 laba bersih perusahaan menurun sebesar Rp. 4.798.778.000 dan kembali meningkat pada tahun 2014 menjadi Rp. 4.839.970.000. Tahun 2015 laba bersih perusahaan sangat menurun sebesar Rp. 2.792.439.000.

\subsubsection{Perkembangan Laba Bersih PT. United Tractors, Tbk}

Berdasarkan hasil penelitian yang dilakukan pada PT. United Tractors, Tbk tentang pengaruh biaya CSR selama 5 tahun (2011-2015) maka perkembangan laba yang terjadi pada perusahaan dapat dilihat pada tabel berikut ini :

Tabel 3 : Perkembangan Jumlah laba bersih PT. United Tractor, Tbk tahun 2011-2015

\begin{tabular}{|c|c|c|c|}
\hline \multirow{2}{*}{ Tahun } & \multirow{2}{*}{ Laba Bersih (Rp) } & \multicolumn{2}{|c|}{ Perkembangan } \\
\cline { 3 - 4 } & & Jumlah (Rp) & Persentase (\%) \\
\hline 2011 & $5,899,506,000$ & - & - \\
\hline 2012 & $5,753,342,000$ & $(146,164,000)$ & $-2.48 \%$ \\
\hline 2013 & $4,798,778,000$ & $(954,564,000)$ & $-16.59 \%$ \\
\hline 2014 & $4,839,970,000$ & $41,192,000$ & $0.86 \%$ \\
\hline 2015 & $2,792,439,000$ & $(2,047,531,000)$ & $-42.30 \%$ \\
\hline \multicolumn{2}{r}{} & $(776,766,750)$ & $-15.13 \%$ \\
\hline
\end{tabular}

Sumber : laporan tahunan (Data sudah diolah) Tahun 2011-2015

Berdasarkan hasil pada tabel 4.5, tahun 2011 perusahaan PT. United Tractor, Tbk menghasilkan laba sebesar Rp. 5.896.506.000, dan pada tahun 2012 laba perusahaan mengalami penurunan sebesar -Rp. 146.164 .000 atau sebesar $-2,48 \%$, dan menjadi $\mathrm{Rp}$. 5.753.342.000. Pada tahun 2013 PT. United Tractor, Tbk kembali mengalami penurunan sebesar -Rp. 954.564.000 atau sebesar 16,59\% dan menjadi Rp. 4.798.778.000. Tahun 2014 laba PT. United Tractor, Tbk naik sebesar Rp. 41,192,000 atau 0.86\% dan menjadi Rp. 4,839,970,000. Dan pada tahun 2015, laba perusahaan kembali turun menjadi Rp. 2,792,439,000 atau mengalami penurunan sebesar -Rp. 2,047,531,000 atau sebesar $-42.30 \%$.

\subsection{Pembahasan}

Berikut ini merupakan hasil analisa data dengan menggunakan analisis regresi sederhana untuk melihat pengaruh biaya coporate social responsibility terhadap laba bersih perusahaan pada PT. United Tractors, Tbk. Analisa data tersebut dapat dilihat pada tabel berikut ini :

Tabel 4: Model Summary

\begin{tabular}{|c|c|c|c|c|}
\hline Model & R & R Square & $\begin{array}{c}\text { Adjusted R } \\
\text { Square }\end{array}$ & $\begin{array}{c}\text { Std. Error of } \\
\text { the Estimate }\end{array}$ \\
\hline 1 & $.768^{\mathrm{a}}$ & .589 & .452 & $9.17627 \mathrm{E} 8$ \\
\hline
\end{tabular}

a. Predictors: (Constant), Biaya CSR

Sumber : Data Olahan SPSS

Berdasarkan tabel 4.8 diperoleh nilai $\mathrm{R}^{2}$ untuk melihat berapa besar pengaruh antara kedua variabel. Pengaruh biaya corporate social responsibility terhadap laba bersih perusahaan yaitu sebesar 0,589 atau $58,9 \%$. Sisanya dari persentase tersebut sebesar $41,1 \%$ dipengaruhi oleh variabel lain yang tidak diketahui dan tidak tercantum dalam hasil penelitian. 
Tabel 5: Coefficients ${ }^{\mathrm{a}}$

\begin{tabular}{|c|c|c|c|c|c|}
\hline \multirow[b]{2}{*}{ Model } & \multicolumn{2}{|c|}{ unstandardized Coefficients } & $\begin{array}{l}\text { Standardized } \\
\text { Coefficients }\end{array}$ & & \\
\hline & B & Std. Error & Beta & $\mathrm{t}$ & Sig \\
\hline $\begin{array}{c}1 \text { (constant) } \\
\text { Biaya } \\
\text { CSR }\end{array}$ & $\begin{array}{c}6.426 \mathrm{E} 9 \\
-.022\end{array}$ & $\begin{array}{r}8.777 \mathrm{E} 8 \\
010\end{array}$ & -.768 & $\begin{array}{c}7.321 \\
-2.074\end{array}$ & $\begin{array}{l}.005 \\
130\end{array}$ \\
\hline
\end{tabular}

a. Dependent Variable : Laba Bersih

Sumber : Data Olahan SPSS

Untuk membuat persamaan regresi linier sederhana $\mathrm{Y}=\mathrm{a}+\mathrm{bX}$ berdasarkan hasil analisis yang ditunjukkan pada tabel 4.9 yang perlu diperhatikan adalah constant (a) merupakan angka konstan dari unstandardized coefficients yaitu sebesar 6,426. Angka tersebut berarti, jika tidak ada biaya CSR (x) maka nilai konsisten laba bersih (y) adalah sebesar 6,426. Biaya CSR (b) merupakan angka koefisien regresi yaitu sebesar -0.022. Angka tersebut berarti, jika setiap kenaikan biaya CSR (x) maka laba bersih (y) akan menurun sebesar $-0,022$. Maka dengan demikian persamaan regresi tersebut, yaitu :

$Y=6,426-0,022 x$

\section{KESIMPULAN DAN SARAN}

\subsection{Kesimpulan}

Berdasarkan hasil peneitian yang dilakukan untuk melihat pengaruh biaya corporate social responsibility terhadap laba bersih perusahaan pada PT. United Tractors, Tbk dapat disimpulkan sebagai berikut :

1. Hasil penelitian berdasarkan $\mathrm{R}^{2}$ yang menunjukkan besarnya pengaruh biaya corporate social responsibility terhadap laba bersih perusahaan PT. United Tractors, Tbk sebesar 0,589 atau $58,9 \%$.

2. Hasil penelitian berdasarkan persamaan regresi yaitu $Y=6,426-0,22 x$ yang artinya jika ada kenaikan biaya corporate social responsibility maka laba bersih perusahaan akan menurun dan sebaliknya.

3. Hasil penelitian berdasarkan nilai signifikan (Sig) menunjukkan sebesar 0,130>0,05 yang artinya tidak ada pengaruh biaya corporate social responsibility terhadap laba bersih perusahaan.

\subsection{Saran}

Berdasarkan hasil penelitian maka penulis memberikan saran sebagai berikut :

1. Pelaksanaan program-program corporate social responsibility sangat baik, terutama perusahaan juga memperhatikan berbagai aspek dalam penerapan CSR. Oleh karena itu disarankan perusahaan untuk tetap mempertahankan penerapan corporate social responsibility secara berkelanjutan.

2. Dengan adanya program corporate social responsibility ini disarankan agar perusahaan juga memperhatikan setiap pengeluaran (biaya untuk CSR) agar perusahaan tidak mengalami penurunan laba dikarenakan biaya CSR yang terlalu besar

\section{DAFTAR PUSTAKA}

Aldina Endarwati. 2013. Analisis Pengungkapan Corporate Social Responsibility terhadap Kinerja Keuangan pada Perusahaan Otomotif di BEI. Jawa Timur. Universitas Pembangunan Nasional. Diakses Juli, 02, 2017.

Arik Handriyani. 2013. Pengaruh Corporate Social Responsibility terhadap Nilai Perusahaan dengan Profitabilitas sebagai Variabel Moderating. Surabaya. Sekolah Tinggi Ilmu Ekonomi Indonesia. Diakses Juli, 02, 2017 
Abiodun, Y, B. 2012. The Impact of CSR on Firm's Profitability in Nigeria. http//www.kau.edu.sa/files/0060841/subjects/impact\%0on\%20profitability.pdf. Diakses Juli, 8, 2017

Bustami, Bastian \& Nurlela. 2010. Akuntansi Biaya. Yogyakarta. Graha Ilmu

Candra Indrawan. 2011. Pengaruh Corporate Social Responsibility terhadap Kinerja Perusahaan. Semarang. Universitas Diponegoro. Diakses Agustus, 08, 2017

Dewa Nistantya. 2010. Pengaruh Corporate Social Responsibility terhadap Profitabilitas Perusahaan. Surakarta. Universitas Sebelas Maret Diakses Agustus, 07, 2017

Dian Pratiwi. 2013. Analisis Pengaruh Biaya Corporate Social Responsibility terhadap Profitabilitas. Makassar. Universitas Hasanuddin. Diakses Juni, 30, 2017

Ignatia Linda Pratiwi. 2014. Pengaruh Biaya CSR terhadap Profitabilitas Perusahaan Perbankan Go-Public di BEi 2011-2012. Universitas Kristen Satya Wacana. Diakses Juli, 02, 2017

Krismaji, Y Anni Aryani. 2011. Akuntansi Manajemen, Edisi 2. Yogyakarta. UPP STIM YPKN.

Ni Luh Kade M. S. 2013. Pengaruh Pengungkapan CSR terhadap Kinerja Keuangan dengan Kepemilikan Asing sebagai Variabel Moderator. Bali. Universitas Udayana. Diakses Juni, 22, 2017

Odetayo, Adeyumi, Sajuyigbe. 2014. Impact of Corporate Social Responsibility on Probability of Nigeria Banks. http//hrmars.com/hrmars_papers/impact_of_corporate_social_responsibility_on_profi tability_of_Nigeria_Banks.Pdf. Diakses Agustus, 10, 2017

Rachmawati. 2010. Pengaruh Sebelum dan Sesudah Penerapan CSR terhadap Profitabilitas pada Perusahaan (studi kasus pada PT.Sermani Steel).Makassar. Universitas Hasanuddin. Diakses Juli, 17, 2017

Rila Gantino. 2016. Pengaruh CSR terhadap Kinerja Keuangan Perusahaan Manufaktur yang terdaftar di BEI periode 2008-2014. Jakarta. Universitas Esa Unggul. Diakses Juli, 17, 2017

Riska Wanda. 2013. Pengaruh Penerapan CSR terhadap Profitabilitas pada Perusahaan Pertambangan. Makassar. Universitas Hasanuddin. Diakses Juli, 17, 2017

Untung, Budi. 2014. Corporate Social Responsibility dalam Dunia Bisnis. Yogyakarta. Penerbit Andi 